\title{
Sensibilização para a Poesia nos Anos Iniciais do Ensino Fundamental
}

\author{
Sensitization for Poetry in the Early Years of Elementary Education
}

Autor

Juliana Regina Pretto. Professora do Instituto Federal do Paraná (IFPR).

E-mail: juliana.pretto@ifpr.edu.br

Recebido em: 22/02/2017 Aprovado em: 22/05/2017

DOl: 10.12957/interag.2017.27494

\section{Relato}

Este texto relata uma experiência decorrente de um projeto de extensão realizado em escolas da Rede Municipal de Ensino de Paranaguá, Paraná. Visando ao incentivo à leitura e à sensibilização para a poesia, o projeto propôs a publicação de mil exemplares do livro Mosaico, com poemas infantis de nossa autoria que foram ilustrados por alunos das escolas dessa rede. O trabaIho de leitura realizou-se com dezessete turmas de seis escolas, totalizando 252 alunos atendidos. $\mathrm{O}$ trabalho de leitura e sensibilização para a poesia pautou-se em estudos sobre leitura literária e formação de leitores (Bordini, Lajolo, Lajolo e Zilberman, Zilberman). As crianças participantes se reconheceram nos temas de muitos dos poemas, fato que possibilitou introduzir o poético na sua imaginação e sensibilizá-las para a poesia.
Abstract

This text reports an experience derived from an extension project carried out in schools from the Municipal Education System of Paranaguá, Paraná. Seeking encourage reading and sensitization for poetry the project proposed the publication of one thousand copies of the book Mosaico, with children's poems of our authorship that were illustrated by students from the schools of the Municipal Education System. The reading work was performed with seventeen classes of six schools, totalizing 252 students attended. The work of reading and sensitization for poetry was based on studies on literary reading and formation of readers (Bordini, Lajolo, Lajolo e Zilberman, Zilberman). The participating children recognized themselves in the themes of many of the poems, which enabled them to introduce the poetic in their imagination and sensitize them to poetry. 
Palavras-chave: Formação de leitores. Incentivo à leitura. Poesia infantil.

Área temática: Educação

Linha de extensão: Incentivo à leitura
Keywords: Formation of readers. Encourage reading. Children's Poetry.

\section{Introdução}

Mosaico é o título de um livro composto por vinte poemas infantis de nossa autoria. A proposta estética dos poemas é captar em palavras o mundo infantil, mostrando um universo de brincadeiras, imaginação, inquietações, temores, saudades, sonhos, fantasias e (por que não?) tristezas. Assim sendo, o objetivo da obra é apresentar à criança temas poéticos nos quais ela possa se reconhecer, podendo, a partir desse reconhecimento, ocorrer uma sensibilização e iniciar o gosto pela leitura de poesia.

Esse livro foi publicado em 2016 por meio de lei de incentivo à cultura; um diferencial da publicação é o fato de haver sido ilustrada por crianças num projeto de extensão vinculado ao Instituto Federal do Paraná que visou ao incentivo à leitura e realizou-se em escolas da Rede Municipal de Ensino de Paranaguá, Paraná, com alunos do 2 ao 5은 anos do Ensino Fundamental. Após a publicação, ocorreu também uma sessão de lançamento com a participação das crianças e das escolas envolvidas no projeto.

O objetivo deste artigo é relatar a experiência decorrente do projeto Mosaico, as ações realizadas, focando mais especialmente na experiência de leitura com as crianças. Como o envolvimento da criança no processo de ilustração requer o trabalho de leitura e sensibilização para a poesia, apostou-se que as atividades do projeto poderiam despertar o gosto pelo texto poético.

\section{A poesia Infantil, a Criança e o Livro Mosaico}

Quando se fala em poesia infantil, é possível que muitas pessoas pensem num texto poético mais fácil de entender, mais simples e talvez até mesmo desprovido de riqueza estilística. Segundo Bordini ${ }^{1}$, atualmente a poesia infantil não é diferente daquela destinada a adultos, já que os elementos poéticos são semelhantes; hoje quem escreve poesia infantil entende a necessidade de superar a assimetria entre a visão do adulto e a cognição infantil, mas sem renunciar ao jogo poético. Acredita-se que superar a assimetria entre a visão do adulto e a cognição da criança pressupõe não subestimar a inteligência e a sensibilidade infantis. A partir do momento que quem escreve para o público infantil entende a criança como um ser capaz de se sensibilizar com a linguagem poética, com o "jogo poético", e aborda temas de interesse para a criança é que se torna possível escrever poesia infantil com qualidade estética e, ao mesmo tempo, capaz de sensibilizar tal público. 
Em relação a isso, Lajolo e Zilberman² afirmam que a atual produção poética para a infância se caracteriza por desvencilhar-se do recorte didático e pedagógico que durante bastante tempo perdurou na poesia destinada ao público infantil; atualmente prima-se por aproximar a poesia infantil da não infantil, abandonando temas que veiculam conselhos, ensinamentos e normas. Evidentemente se a poesia escrita para adultos não se destina a ditar normas e dar conselhos e ensinamentos, é de se esperar que a destinada a crianças siga os mesmos caminhos; qualquer poesia que se destine a fins pedagógicos e/ou moralizantes levanta sérias dúvidas em relação à sua qualidade estética.

Ao escrever o livro Mosaico, tentou-se aproximar a poesia produzida para a criança da poesia para adultos, sem subestimar a inteligência e sensibilidade infantis. Para isso, foram selecionados temas como medo, tristeza, saudade, dúvidas, inquietações e reflexão sobre os próprios sentimentos. Afinal, crianças também se entristecem, sentem saudade, medo, angústia, ainda que por motivos diferentes daqueles que causam esses mesmos sentimentos nos adultos. No livro Mosaico, esses temas estão presentes: a tristeza de uma pipa que ficou presa nos fios elétricos, o medo do escuro e da tempestade, a tristeza causada pela saudade de alguém, a reflexão sobre um coração indeciso a partir da sua comparação à indecisão do vai e vem do mar, entre outros. Além desses, temas como a imaginação e as brincadeiras próprias da infância também estão presentes em poemas que tratam, por exemplo, de brincar na chuva, com bolhas de sabão ou de ver imagens nas nuvens.

Além disso, também se optou por textos curtos, com linguagem sintética, altamente condensada e emotiva, com possibilidade de interessar inclusive a crianças maiores que não têm o hábito de ler poesia. De acordo com Pondé ${ }^{3}$, a poesia é um meio de criar novas linguagens e respeitar o mundo da criança, que tem uma lógica particular, pois a sua apreensão é emocional e globalizante; por isso, a poesia, com sua linguagem altamente condensada e emotiva, sensibiliza-a intensamente. A poesia, seja para o público infantil ou adulto, não se ocupa de apresentar a experiência humana de forma objetiva, mas sim de maneira emocional e inovadora por meio de recursos linguísticos que objetivam chamar a atenção do destinatário para a mensagem. É, portanto, por meio da sua linguagem emotiva, subjetiva e conotativa que a poesia se aproxima do emocional infantil e certamente será familiar à criança.

No livro Mosaico, aposta-se na sensibilização para a poesia como uma forma de auxiliar o desenvolvimento da criatividade e expressão da criança, assim como da sua própria sensibilidade em relação à sua visão de mundo; além disso, acredita-se que a poesia pode auxiliar a criança a compreender que a linguagem é capaz de refletir as nossas experiências no mundo. A esse respeito, Averbuck ${ }^{4}$ afirma que a questão do desenvolvimento da sensibilidade para o texto poético relaciona-se ao problema do desenvolvimento da criatividade, da expressão e da compreensão da linguagem como representação da experiência humana, tendo a poesia um papel importante no crescimento da personalidade da criança e na formação do seu psiquismo, na ampliação do psíquico, do individual e da cognição do universo realizado pela linguagem. Para Zilberman ${ }^{5}$, a leitura da literatura é importante por colaborar para o fortalecimento do imaginário, pois é com a imaginação que solucionamos problemas. Portanto, a leitura da literatura colabora para o desenvolvi- 
mento da criatividade, da expressão e da imaginação, e a poesia pode auxiliar no desenvolvimento e formação da criança, na sua visão de mundo, na sua sensibilidade.

\section{A Leitura e a Formação de Leitores no Projeto Mosaico}

Para realizar as atividades de leitura dos poemas do livro Mosaico com os alunos das escolas, teve-se em conta a observação dos recursos linguísticos e dos temas dos poemas, explorando os seus elementos para a interpretação global da obra e valorizando as interpretações individuais dos alunos para auxiliar na formação de um leitor imaginativo, aberto ao poético e à criatividade. De acordo com Gusmão-Garcia e Silva ${ }^{6}$, se a leitura não for reduzida à pura descodificação técnica, mas sim se a criança for levada a se dar conta de todos os elementos do texto (mensagem intelectual, valor estético, significações múltiplas de um mesmo elemento, variações possíveis da interpretação individual etc.), certamente se estará formando um leitor disponível e aberto ao poético, ao fantástico, ao imaginário, ao lúdico e à criação, aspectos "que, além da lógica e da gramática, fazem parte do esquema interpretativo da criança". Lajolo ${ }^{7}$ sugere que as atividades de leitura se centrem no significado mais amplo do texto, "significado que não se confunde com o que o texto diz, mas reside no modo como o texto diz", e com isso os elementos geradores de atividades devem levar a criança a refletir sobre o significado geral do texto.

No trabalho de incentivo à leitura também teve-se em conta a necessidade de proporcionar às crianças participantes a oportunidade de compartilhar as suas leituras e socializar-se, já que, por meio da leitura e das ilustrações que criaram, os alunos puderam expressar a sua interpretação do poema escolhido e compartilhá-la tanto no âmbito da escola, com os colegas, quanto no âmbito da comunidade, na sessão de lançamento da obra, fomentando o diálogo, a troca de experiências e o contraste de gostos e opiniões sobre a obra literária. A esse respeito, Zilberman ${ }^{8}$ menciona que a leitura do texto literário possui um ângulo individual e outro social; enquanto no primeiro a leitura permite ao sujeito ampliar as suas experiências a partir das vivências transmitidas pelo texto, no segundo o leitor socializa a experiência, coteja as conclusões com as de outros leitores e discute preferências, o que leva os indivíduos a práticas socializantes.

Já a atividade de desenhar o texto lido é relevante para estimular a inventividade da criança e desencadear a sua imaginação. Averbuck ${ }^{4}$ pontua sobre a importância de explorar as possibilidades de inventividade, com o uso de desenhos, jogos visuais, atividades rítmicas, jogos com as palavras do poema. Acredita-se também que o desenho faz com que a criança expresse a sua interpretação do texto sem ter que explicá-lo com palavras, ou seja, o pictórico facilita a exteriorização dessa expressão para a cognição infantil.

\section{As Atividades do Projeto}

Durante o ano de 2016, o projeto de extensão intitulado Mosaico esteve vinculado ao Comitê de Pesquisa e Extensão do Instituto Federal do Paraná e foi patrocinado pela Fundação Municipal de Cultura "Nelson de Freitas Barbosa", de Paranaguá, sendo 
desenvolvido ao longo desse ano. Além disso, o projeto também obteve a anuência da Secretaria Municipal de Educação e Ensino Integral de Paranaguá para desenvolver-se em turmas das escolas dessa rede de ensino.

Numa primeira etapa, ocorreu a divulgação do projeto nas escolas e o processo de leitura e ilustração dos poemas. Foi feito contato com as escolas e o projeto foi divulgado. A metodologia do trabalho em sala de aula para a leitura e ilustração dos poemas foi definida pela própria autora, que realizou as atividades com as crianças com a participação das professoras regentes das turmas. Foi feita a leitura de poemas da obra e a produção das ilustrações, processo que também foi fotografado.

Para o trabalho de leitura e ilustração dos poemas, procedeu-se da mesma forma em todas as turmas. Primeiramente apresentou-se aos alunos o projeto como um todo (etapas, seleção dos desenhos, publicação e lançamento), propondo a participação das crianças no projeto. Após o aceite dos alunos, eram lidos de três a cinco poemas de forma bastante mediada, pois antes da leitura averiguavam-se as reflexões prévias das crianças sobre o tema de cada poema e em seguida fazia-se a leitura de um poema de cada vez em voz alta, enfatizando a sonoridade das palavras, a entonação de declamação e a postura corporal. Juntos, levantavam-se as ideias em relação ao que mais chamava a atenção das crianças sobre cada texto. Também se discutiam ideias sobre os elementos dos poemas que poderiam ser desenhados e a partir daí se procurava desencadear a imaginação das crianças de forma conjunta. Nesse momento ocorria uma forte troca de experiências: cada aluno dizia de qual dos poemas lidos havia gostado mais e por quê. Assim, ocorria a socialização da leitura. Finalmente, entregava-se o material necessário para a realização dos desenhos, papel em formato A4, lápis de cor e giz de cera, e as crianças realizavam seus desenhos. Durante a feitura das ilustrações, as crianças mostravam seus trabalhos aos colegas, trocavam ideias sobre a leitura dos textos e, assim, dava-se continuidade à socialização da leitura.

Inicialmente foi previsto o trabalho com cinco poemas em cada turma; no entanto, notou-se que, apesar de os textos serem curtos, quando se terminava a leitura do terceiro poema, as crianças já estavam impacientes para realizar seus desenhos. Por isso, diminuiu-se para três poemas por turma, o que se revelou ideal.

Ao final da primeira etapa, para selecionar as ilustrações que fariam parte da publicação, foi instituída uma comissão julgadora, da qual fizeram parte membros integrantes da Secretaria Municipal de Educação e Ensino Integral, da fundação que patrocinou o projeto e do Instituto Federal do Paraná. Essa comissão selecionou uma ilustração por poema para fazer parte da obra. Posteriormente, os integrantes do projeto escolheram uma ilustração extra para a contracapa do livro.

Numa segunda etapa, se procedeu à elaboração da publicação. Foi feita a diagramação do livro, foi solicitado o ISBN e foi elaborada a ficha catalográfica. Foram feitas diversas revisões e conferências tipográficas do boneco do livro e se encaminhou o material para impressão. Portanto, a publicação foi feita pelos integrantes do projeto de forma independente, sem a atuação de editora.

Numa terceira etapa, ocorreu a fase de lançamento, divulgação e distribuição. Foram definidas as atividades do evento de lançamento da obra, e a Secretaria Municipal de 
Educação e Ensino Integral cedeu o espaço, um auditório dessa secretaria. O saguão desse auditório foi o espaço escolhido para expor os desenhos de todos os alunos participantes e as fotos do processo de leitura e ilustração. A data escolhida foi a semana do Dia das Crianças. Foi elaborada a divulgação do lançamento, o material de divulgação (cartaz e convite). O lançamento ocorreu com a presença da autora e dos ilustradores, bem como das demais crianças participantes do projeto, com suas professoras e outros representantes de escolas. Após a cerimônia de premiação dos ilustradores, os livros foram distribuídos tanto às escolas participantes quanto às demais escolas da Rede Municipal de Ensino. Ao todo, trinta e três escolas foram beneficiadas pelo projeto; cada uma delas recebeu em média vinte exemplares do livro. No final do lançamento, as crianças puderam ver os desenhos e fotos dos alunos da sua e das demais escolas na exposição realizada no saguão do auditório. Por ocasião do lançamento, as crianças também puderam conversar e trocar experiências, socializando a sua leitura e suas impressões sobre o projeto com crianças de outras escolas. Além disso, também puderam desfrutar do coquetel de lançamento, que contou com salgados, doces e sucos. Cabe ressaltar que a exposição permaneceu no saguão do auditório por oito dias, o que possibilitou à comunidade em geral apreciar os trabalhos produzidos no projeto.

\section{Algumas Considerações sobre o Projeto e suas Contribuições}

Um dos pontos mais positivos do projeto certamente foi a motivação que gerou nos alunos. Isso se deu primeiramente devido à possibilidade de ter seus trabalhos publicados num livro e ao fato de seus desenhos serem expostos em local público para visitação. Como o "prêmio" para o aluno que tivesse seu desenho selecionado seria um exemplar do livro, essa possibilidade também gerou muito interesse. Chamou-nos a atenção crianças que relataram ter gosto pela leitura, mas declaravam não ter livros para ler em casa, sendo que gostariam de tê-los.

Além dessas questões, outro fator motivador foi o próprio contato com a autora. Geralmente os alunos ficavam curiosos em relação ao fazer poético de um escritor, à obra, entre outros, e dirigiam à autora perguntas do tipo: Você escreve só para crianças? Você já publicou quantos livros? Demora muito para uma pessoa "ser" escritor? Na internet encontro outros poemas seus para eu ler na minha casa? Surgiam até mesmo perguntas pessoais, como: Você tem filhos? Você é casada?

Uma das professoras com quem estabelecemos maior vínculo relatou os poemas de que os alunos mais gostaram e que alguns textos geraram comentários em aulas posteriores. Nas turmas da escola em que essa professora leciona, o trabalho foi especialmente produtivo, pois esta trabalha com muitos textos poéticos de autores consagrados, como Cecília Meireles e Vinícius de Moraes, por exemplo. Além disso, a professora já realiza um trabalho de forma que a leitura dos textos incentiva a inventividade, gerando atividades como dramatizações (teatrinhos), desenhos, atividades manuais, cartazes, etc. Assim, a proposta de ilustrar poemas foi muito bem recebida pelas suas turmas, 
que ficaram especialmente animadas com o nosso trabalho, além de demostrarem mais criatividade e imaginação, o que é de se esperar quando se tem em conta o fato de já terem contato com o texto poético com frequência.

Como escritora, o contato com o público-alvo foi uma experiência inigualável, já que foi possível perceber quais poemas agradaram mais e quais temas chamaram mais a atenção, o que dá a possibilidade de redimensionar o trabalho como escritora. Evidentemente já se imaginava que os poemas que contêm rimas chamariam mais a atenção das crianças devido à sonoridade. No entanto, poemas com versos brancos interessaram aos pequenos de forma surpreendente e geraram muito debate. Um poema que interessou especialmente aos meninos foi aquele que trata da tristeza por perder a pipa num fio elétrico, fato compreensível se considerarmos que esse brinquedo faz parte do seu mundo. Um poema que trata da reflexão sobre o amor romântico por meio do "beijo" dado pelo beija-flor às flores interessou muito, especialmente às meninas. O poema mais desenhado, que suscitou muito debate no momento da leitura, não contém rimas e trata do medo do escuro, temor muito frequente em crianças; por meio das ilustrações desse poema foi possível notar, inclusive, os temores de cada criança (fantasmas, monstros, bruxas, seres extraterrestres, etc.). Esses são alguns exemplos de como as crianças se reconheceram nos temas dos poemas; acredita-se que tal reconhecimento possa ter sido a entrada para introduzir o poético na sua imaginação e sensibilizá-los para a poesia. Por meio da leitura e do debate desses temas com a autora e com os colegas, ou seja, do compartilhar a leitura e suas experiências - seus medos, tristezas e fantasias - foi possível estabelecer uma sensibilização para o texto poético.

Enfim, o objetivo de sensibilizar o público para a poesia foi atingido com êxito e espera-se que tenha sido apenas uma semente, pois, como uma quantidade significativa de exemplares foram entregues a cada escola, a leitura da obra poderá ser feita de forma integral com os alunos pelas professoras regentes, além de poderem ser emprestados pelas crianças.

O projeto foi muito bem aceito tanto pelas direções das escolas participantes quanto pelos alunos, gerou motivação e muitos deles se esforçaram bastante durante o processo de leitura e ilustração. Evidentemente algumas crianças sentiram-se menos ou pouco motivadas, fato totalmente compreensível, já que nem todos têm os mesmos interesses. No entanto, de maneira geral, os resultados nos pareceram bastante produtivos.

\section{Referências}

1. BORDINI, Maria da Glória. Para a poesia infantil ser poesia. Tigre Albino, Porto Alegre, v. 1, n. 1, p. 1-8, nov. 2008. Disponível em: <http://www.tigrealbino.com.br> Acesso em: 12 de janeiro de 2016.

2. LAJOLO, Marisa.; ZILBERMAN, Regina. Literatura infantil brasileira: história e histórias. São Paulo: Ática, 2007. 186 p.

3. PONDÉ, Glória Maria Fialho. Poesia para crianças: a mágica da eterna infância. Tigre Albino, Porto Alegre, v. 2, n. 2, p. 1-6, mar. 2009. Disponível em: <http://www. 
tigrealbino.com.br/> Acesso em: 12 de janeiro de 2016.

4. AVERBUCK, Ligia Morrone. A poesia e a escola. Tigre Albino, Porto Alegre, v. 1, $n$. 2, p. 1-1, mar. 2008. Disponível em: <http://www.tigrealbino.com.br/> Acesso em: 12 de janeiro de 2016.

5. ZILBERMAN, Regina. A leitura e o ensino da literatura. Curitiba: Intersaberes, 2012. 257p.

6. GUSMÃO-GARCIA, Silvia Craveiro; SILVA, Antonio Manoel dos Santos. A criança, o livro e o gosto pela leitura. Olho d'água, São José do Rio Preto, v. 1, n. 1, p. 7-14, 2009. Disponível em: <http://www.olhodagua.ibilce.unesp.br/> Acesso em 12 de janeiro de 2016.

7. LAJOLO, Marisa. Do mundo da leitura para a leitura do mundo. São Paulo, Ática, 1993. $112 \mathrm{p}$.

8. ZILBERMAN, Regina. O papel da literatura na escola. Via Atlântica, n. 14, p. 11-22, dez. 2008. Disponível em: <http://www.revistas.usp.br/viaatlantica> Acesso em: 12 de janeiro de 2016. 